\title{
Design Thinking: inovação e versatilidade em diferentes áreas do conhecimento
}

Maria Paulina de Assis ${ }^{1}$; Lucas Horácio Zacura ${ }^{2}$; Joyce Rodrigues de Souza Costa ${ }^{3}$; Juliana Pereira de Araujo ${ }^{4}$; Rita Tatiana Cardoso Erbs ${ }^{5}$; Fabiana Jordão Martinez ${ }^{6}$

\section{Resumo}

A Incubadora de Empreendimentos Sociossolidários - INESSOL, da Universidade Federal de Goiás - campus de Catalão, realiza projetos de extensão universitária no âmbito da educação popular, em processos de incubação de desenvolvimento de cooperativas de trabalhadores radicados na cidade. A INESSOL tem utilizado a metodologia do Design Thinking para a compreensão da realidade das cooperativas e também para a intervenção nos processos de intervenção. Daí surge a necessidade de aprofundamento dos conhecimentos sobre esta metodologia por parte de seus membros. O presente trabalho tem como objetivo pesquisar o estado da

\footnotetext{
${ }^{1}$ Doutora em Educação: Currículo pela Pontifícia Universidade de São Paulo, pesquisadora em Design Thinking e Mobile Learning, pesquisadora da Incubadora de Empreendimentos Sociossolidários_(INESSOL), professora de Psicologia da Educação da Universidade Federal de Goiás, campus de Catalão. Email: paulina@ufg.br.

${ }^{2}$ Graduando em Psicologia bacharel e licenciatura pela Universidade Federal de Goiás (UFG), campus Catalão; participante da Incubadora de Empreendimentos Sociossolidários_(INESSOL), também atuando na pesquisa em Mobile Learning, além de outro projeto de extensão, com ênfase na área psicossocial, Psicologia na Comunidade.

${ }^{3}$ Graduanda do segundo período de Pedagogia da Universidade Federal de Goiás, campus de Catalão. participante da Incubadora de Empreendimentos Sociossolidários (INESSOL)

${ }^{4}$ Doutora em Educação, professora de didática da Universidade Federal de Goiás, campus de Catalão), coordenadora da Incubadora de Empreendimentos Sociossolidários_(INESSOL).

${ }^{5}$ Graduada em psicologia - PUCRS, mestre em educação - PUCRS e doutora em educação - PUCRS, professora de psicologia da educação da Universidade Federal de Goiás e integrante do projeto de extensão da Incubadora de Empreendimentos Sócio Solidários - Inessol

${ }^{6}$ Doutora em Ciências Sociais e mestra em Antropologia social. Professora efetiva da Universidade Federal de Goiás, Regional de Catalão e extensionista do projeto INESSOL - Incubadora de Empreendimentos Sociossolidários.
} 
arte do Design Thinking no Brasil, com foco na versatilidade de seu uso, considerando as várias possibilidades de aplicação desta metodologia, em diferentes contextos e áreas do saber, tais como inovação organizacional, inovação educativa, imersão e implementação de projetos em comunidades, extensão universitária, incubação de projetos por incubadoras sociais como a INESSOL, dentre outros projetos possíveis nas áreas educacionais e sociais. A metodologia de pesquisa será a busca na Internet - no período compreendido pelos últimos dez anos (de 2007 a 2016) - de artigos, vídeos, acadêmicos, sites de consultorias, cursos online e bases de dados de pesquisa científica. A partir da pesquisa será feita uma compilação dos achados, que, por sua vez, serão usados para a fundamentação teórica deste artigo. Esperase obter como resultado um repositório de objetos de aprendizagem armazenados em plataformas "em nuvem" e também uma pasta específica no gerenciador de referências EndNote, para apoio a futuras pesquisas sobre Design Thinking. Esta ação será útil para os trabalhos futuros da INESSOL, contribuindo para o desenvolvimento acadêmico dos alunos e professores do grupo de pesquisa e também da comunidade acadêmica como um todo, tendo em vista que os trabalhos ficarão disponíveis na grande rede.

Palavras Chave: Design Thinking; Incubadora Social; Extensão 